DOI: $10.12957 /$ teias.\%Y.55792

\title{
POR UMA ESCOLA PARA TODOS: trabalho colaborativo da fonoaudiologia educacional
}

Paula Mieco Koizumi Masuyama

\section{Resumo}

Lacunas no aprendizado de algumas crianças que estão à margem da política de inclusão se tornam mais evidentes no momento que estamos vivenciando. $\mathrm{O}$ artigo sintetiza a dissertação de mestrado em Educação e analisa a contribuição e os desafios do trabalho interdisciplinar entre a Fonoaudiologia e a Educação para a formação continuada de professores dos anos iniciais do ensino fundamental sobre os problemas de aprendizagem da linguagem escrita. A investigação de natureza qualitativa, do tipo pesquisa intervenção com nuances do modelo construtivo-colaborativo, foi desenvolvida por meio de um programa de formação continuada de professores, na modalidade a distância. Os principais instrumentos de coleta de dados foram o questionário e as narrativas escritas. A análise dos dados ocorreu por meio da análise de conteúdo. Os resultados indicaram que o trabalho articulado entre as respectivas áreas possibilitou a construção de um novo saber, a partir do entendimento que somos únicos.

Palavras-chave: Inclusão; Fonoaudiologia Educacional; Formação colaborativa.

FOR A SCHOOL FOR ALL: collaborative work of educational speech therapy

\begin{abstract}
Gaps in the learning of some children who are outside the inclusion policy become more evident at the moment we are experiencing. The article summarizes the Master's thesis in Education and analyzes the contribution and challenges of interdisciplinary work between Speech Therapy and Education for the continuing education of teachers in the early years of elementary school on the problems of learning the written language. The qualitative research, of the intervention research type with nuances of the constructive-collaborative model, was developed through a program of continuing education of teachers, in the distance modality. The main data collection instruments were the questionnaire and written narratives. Data analysis took place through content analysis. The results indicated that the articulated work between the respective areas enabled the construction of a new knowledge, based on the understanding that we are unique.
\end{abstract}

Keywords: Inclusion; Educational Speech Therapy; Collaborative training.

POR UNA ESCUELA PARA TODOS: trabajo colaborativo de fonoaudiología educativa

Resumen

Las brechas en el aprendizaje de algunos niños que están fuera de la política de inclusión se hacen más evidentes en el momento que estamos viviendo. El artículo resume la Tesis de Maestría en Educación y analiza el aporte y desafíos del trabajo interdisciplinario entre Logopedia y Educación para la formación continua de los docentes en los primeros años de la escuela primaria sobre los problemas del aprendizaje de la lengua escrita. La investigación cualitativa, del tipo investigación de intervención con matices del modelo constructivo-colaborativo, se desarrolló a través de un programa de formación continua de docentes, en la modalidad a distancia. Los principales instrumentos de recolección de datos fueron el cuestionario y las narrativas escritas. El análisis de datos se realizó a través del análisis de contenido. Los resultados indicaron 
DOI: $10.12957 /$ teias. $\%$ Y.55792

que el trabajo articulado entre las respectivas áreas permitió la construcción de un nuevo conocimiento, basado en el entendimiento de que somos únicos.

Palabras clave: Inclusión; Terapia del habla educativa; Formación colaborativa.

\section{INTRODUÇÃO}

O mundo está vivenciando um período de muitas incertezas e desafios com a pandemia do COVID - 19 em que as ações estão pautadas nas experiências exitosas e não exitosas dos países e, como consequência, todos os setores sofrem impactos especialmente a Educação.

Tal fato é preocupante visto que as lacunas no aprendizado de algumas crianças que estão à margem da política de inclusão se tornam mais evidentes, pois de acordo com o Relatório de Monitoramento Global da Educação:

Mesmo antes da atual pandemia, um em cada cinco adolescentes, jovens e crianças estava totalmente excluído da educação. Além disso, a existência de estigmas, estereótipos e discriminação significa que outros milhões são excluídos nas próprias salas de aula. (UNESCO, 2020, p. 5).

Isso significa que, apesar de lacunas no aprendizado já serem evidenciadas no ensino presencial, nesse momento de ensino remoto se tornam mais evidentes principalmente para àquelas que estão à margem da política de inclusão e o impacto tende ser o mesmo do que já estava ocorrendo que era a patologização da Educação.

Caminhar rumo a Educação para todos mostra que ainda é preciso romper com alguns paradigmas conservadores, especialmente a ideia higienista, que limitam as ações e instigam a estigmatização, a patologização e, por fim, a exclusão.

A Educação do século XXI precisa suplantar a ideia restrita de inclusão. Incluir não se restringe a pessoas com deficiência ou que fogem dos padrões de normalidade estabelecida pela sociedade. Por isso, consideramos que "[...] continua sendo um tema atual e polêmico nas diversas esferas, principalmente, na educação e na saúde desencadeando algumas ações que caminham na contramão do seu verdadeiro sentido - a Educação para todos" (MASUYAMA; RINALDI, 2020, p. 7).

Incluir está imposto e sabemos que não é simples, pois necessita uma nova configuração dos modos de ser e agir diante de um processo que está vigorando e não é possível esperar as condições ideais para fazer acontecer (MANTOAN, 2017).

Ao acompanhar o Relatório de Monitoramento Global da Educação (2020, 2019, 2014) verificamos que a desigualdade referente às oportunidades educacionais estão cada vez mais graves ao se pensar em educação de qualidade, melhoria de ensino cujas consequências são evidenciadas nas avaliações a respeito da aprendizagem.

O Relatório de Monitoramento Global de Educação para Todos - EPT (UNESCO, 2014) indica a existência de uma crise mundial da aprendizagem enfatizando a existência de estudantes sem as habilidades básicas de alfabetização e operações matemáticas.

É válido dizer que houve algumas conquistas da área educacional em nosso país como o aumento do número de matrículas em todos os níveis (Educação Infantil, Ensino Fundamental e Ensino Médio), a construção de sistemas de avaliação entre outros. No entanto, não houve mudanças significativas nos níveis de aprendizado do estudante este considerado um dos principais desafios (TODOS PELA EDUCAÇÃO; MODERNA, 2019). Tais resultados também são 
DOI: $10.12957 /$ teias. $\%$ Y.55792

confirmados pelas pesquisas publicadas pela Organização das Nações Unidas para a Educação, a Ciência e a Cultura ${ }^{1}$ (UNESCO):

As pesquisas mostram que grande parcela dos alunos de diferentes níveis educacionais apresenta deficiências de aprendizagem em disciplinas críticas. A baixa absorção de conceitos científicos prejudica a inclusão desses indivíduos na sociedade moderna (UNESCO, 20--).

Nesse contexto, o termo deficiências de aprendizagem é compreendido como a distorção entre idade e ano/série escolar, o fraco domínio da leitura e da escrita e o analfabetismo. A ênfase centrada nestas "deficiências" traz certa preocupação uma vez que tem gerado equívocos no âmbito escolar direcionando a questão para a 'patologização' ou para a 'pedagogização' da aprendizagem.

O termo patologização expressa uma condição orgânica e inclui a medicalização dos estudantes, já a pedagogização surgiu para combater a medicalização da aprendizagem e caracteriza somente uma falha do trabalho do professor desconsiderando a questão orgânica (GIROTO, 2005). Assim, polarizar os conceitos não contribui para a busca de estratégias e alternativas que favoreçam uma ação pedagógica que propicie o aprendizado da linguagem escrita pelos estudantes. Não é incomum encontrar professores que ainda atribuem o baixo desempenho acadêmico a um problema na criança, à falta de infraestrutura, à falta de apoio do gestor, à pouca participação e às condições socioeconômicas da família, entre outros. Consequentemente, estes acabam sendo vistos de forma fragmentada, rotulados ou até mesmo excluídos das atividades em sala de aula, aumentando cada vez mais a defasagem em relação ao nível de escolaridade.

É preciso entender que somos únicos, singulares e não limitar os espaços de aprendizagem. Lanuti $(2015$, p. 28) aponta para a necessidade da transformação da prática pedagógica, “[...] de modo que as diferenças que caracterizam os estudantes sejam valorizadas para o desenvolvimento de um trabalho pedagógico em uma perspectiva de educação inclusiva, atendendo às necessidades da escola contemporânea".

Diante do exposto e por considerar a Educação um espaço multifacetado, entendemos que a inserção do fonoaudiólogo nesta área se torna relevante, já que com os seus conhecimentos específicos pode contribuir para o desenvolvimento do indivíduo e para a melhoria da qualidade de vida. Tais aspectos vão ao encontro das propostas da política educativa em vigor.

\section{Interface entre Educação e Fonoaudiologia}

A Fonoaudiologia é concebida como uma área da Saúde e da Educação, pois "é na escola que o profissional fonoaudiólogo se depara com todas as áreas de competência da ciência fonoaudiologia, ou seja, comunicação oral e escrita, vOz, fala, audição e outras" (RIBAS; SERRATO, 2010, p. 9).

A regulamentação da atuação da Fonoaudiologia na área da Educação tem base em fundamentos legais referentes ao artigo $4^{\circ}$ inciso L da Lei 6965/81 a qual estabelece que "é da competência do fonoaudiólogo participar de equipe de orientação e planejamento escolar, inserindo aspectos preventivos ligados a assuntos fonoaudiológicos" (BRASIL, 1981).

Pautada nesta lei, existe a resolução do Conselho Federal de Fonoaudiologia No 309/05 (CFFa, 2005) que amplia e estabelece a atuação dessa profissão na educação:

\footnotetext{
${ }^{1}$ Reportagem disponível em: <http://www.unesco.org/new/pt/brasilia/education/educational-quality/>. Acesso em: 10 abr. 2015.
} 
DOI: $10.12957 /$ teias. $\%$ Y.55792

Cabe ao fonoaudiólogo, desenvolver ações, em parceria com os educadores que contribuam para a promoção, aprimoramento e prevenção de alterações dos aspectos relacionados à audição, linguagem (oral e escrita), motricidade oral e voz e que favoreçam e otimizem o processo de ensino e aprendizagem.

Nesse contexto, atuação fonoaudiológica no âmbito educacional e escolar se desvencilha de concepções provenientes da epistemologia da profissão com base no modelo clínico-médico (RIBAS; PAZINI, 2010).

A incompreensão sobre o 'porquê' a criança "não aprende" gera conflitos no ambiente escolar e o professor sozinho, muitas vezes, não tem condições para chegar a esse entendimento devido ao fato de não ter o conhecimento ou ter dificuldade para lidar com a diferença dos estudantes que hoje estão na escola e na sala de aula (MASUYAMA; RINALDI, 2020; LANUTI, 2015; CAPELLINI; GERMANO; CUNHA, 2009; LEONARDO; BRAY; ROSSATO, 2009). Opinião corroborada por Peña (2001, p. 59) quando afirma que "muito raramente as falhas pedagógicas dos professores era um argumento para explicar o insucesso e a repetência. Em geral, a causa do fracasso era atribuída aos alunos tidos como incompetentes, preguiçosos etc.".

Tal situação recentemente foi confirmada por um estudo empírico realizado por Masuyama e Rinaldi (2012) ao identificarem o desconhecimento dos professores e gestores de uma escola de anos iniciais do ensino fundamental quanto às diferenças entre dificuldades e distúrbios de aprendizagem, a dificuldade em trabalhar com a criança que não demonstra interesse pelas atividades propostas, em relacionar teoria e prática, em se verem como responsáveis pelo aprendizado dos estudantes, em atender a todos na mesma proporção diante de uma sala heterogênea, em saber lidar com a indisciplina e o anseio por novas propostas de ação para as crianças com problemas de aprendizagem e de comportamento.

O cotejo dessas situações remete a premência de outras especialidades atuando em colaboração na educação para assessorar, acompanhar, refletir e a interagir com os profissionais da escola para implementar ações que favoreçam o ensino e a aprendizagem dos estudantes.

Tendo essa ideia como referência acreditamos que, entre outras medidas que extrapolam a escola e a sala de aula, um dos procedimentos essenciais é investir na formação de professores para a melhoria da qualidade do ensino, uma vez que há indicadores que apontam que professores melhor preparados podem ensinar melhor seus estudantes, embora essa não seja uma relação linear (RINALDI, 2009).

Tal concepção corrobora com o Relatório de Monitoramento Global de EPT (2014), o que defende que a qualidade educacional depende, principalmente, da formação de professores para a renovação do processo de ensino e aprendizagem em sala de aula, na tentativa de auxiliar na melhoria da crise global de aprendizagem.

Desse modo, o objetivo geral da pesquisa foi analisar a contribuição e os desafios do trabalho interdisciplinar entre a Fonoaudiologia e a Educação para a formação continuada de professores dos anos iniciais do ensino fundamental sobre os problemas de aprendizagem da linguagem escrita.

\section{TECENDO CAMINHOS COLABORATIVOS: DELINEAMENTO DA PESQUISA}

O artigo sintetiza a dissertação de mestrado em Educação e analisa a contribuição e os desafios do trabalho interdisciplinar entre a Fonoaudiologia e a Educação para a formação continuada de professores dos anos iniciais do ensino fundamental sobre os problemas de aprendizagem da linguagem escrita. 
DOI: $10.12957 /$ teias. $\%$ Y.55792

Ao considerar o tema desta pesquisa, sabemos que envolve uma série de discussões e reflexões acerca da prática docente e da inserção da Fonoaudiologia no campo da educação, mais especificamente na formação continuada de professores. Esse processo demandou um intenso e cuidadoso levantamento sobre a produção bibliográfica a despeito do objeto investigado, bem como a organização de uma análise sistemática que permitisse a apreensão da informação e das evidências disponíveis na literatura sobre o tema e o contexto das investigações.

O arcabouço teórico-metodológico do trabalho teve como enfoque a pesquisa qualitativa e foi pautado na pesquisa-intervenção, com nuances do modelo construtivo-colaborativo (RINALDI, 2006; 2009), considerando que a realidade estudada é complexa e o pesquisador é um sujeito ativo em todo o processo, que age e influencia o ambiente, bem como é também influenciado por ele (RINALDI, 2009).

Nessa perspectiva, foi organizada como um programa de formação continuada na modalidade a distância e composta por um grupo de 22 professores em exercício nos anos iniciais do ensino fundamental da rede pública de ensino (sujeitos da pesquisa), a formadora pesquisadora e duas pedagogas colaboradoras.

O desafio foi pensar em um programa de formação continuada que contribuísse para que os professores desenvolvessem habilidades para serem críticos, reflexivos, investigativos e com a capacidade de identificar, resolver problemas e, consequentemente, de ensinar (MIZUKAMI et al., 2003) estudantes com problemas de aprendizagem da linguagem escrita. Ainda, segundo as autoras, a construção do conhecimento docente ocorre por meio da intervenção que desequilibra as certezas que dão o suporte a prática e, assim, permite a construção de um novo conhecimento.

Por se tratar de um trabalho de parceria entre pesquisadora, colaboradoras e professores, a perspectiva construtivo-colaborativa tem como objetivo proporcionar o diálogo, o envolvimento entre os envolvidos, trocas e desenvolvimento profissional, formando-os investigadores da própria prática (PIMENTA, 2006; ELLIOT, 2001; PEREIRA, 2001), ou seja, os professores ganham vez e voz em todo o processo.

Tais premissas são coerentes com os objetivos deste trabalho, uma vez que valoriza a prática do professor e seu contexto para a aquisição ou construção de novos saberes e a realização da intervenção, a qual espera-se gerar um impacto positivo na prática do professor e, consequentemente, no desempenho escolar do estudante, bem como vislumbrar possíveis contribuições da Fonoaudiologia na formação continuada de professores.

Todos os aspectos éticos ${ }^{2}$ foram respeitados, bem como a não identificação dos sujeitos da pesquisa, como forma de anonimato garantido no Termo de Consentimento Livre e Esclarecido (TCLE). Para tanto, os participantes serão identificados pela sigla PC (professor cursista).

A intervenção foi desenvolvida a partir de um programa de formação continuada de professores na modalidade a distância, via Ambiente Virtual de Aprendizagem (AVA) com suporte na plataforma Moodle, por meio do Portal Edutec - Educação e Tecnologia. Caracterizada como atividade de extensão universitária na Universidade Estadual Paulista (UNESP), com carga horária de 180 horas, na modalidade de Aperfeiçoamento e com certificação da Pró-Reitoria de Extensão Universitária (PROEX) da Unesp.

O programa foi estruturado para facilitar o acesso e manuseio dos professores cursistas no AVA-Moodle, considerando que teríamos participantes com diferentes níveis de experiência na

\footnotetext{
2 Inicialmente, submetemos o projeto de pesquisa para aprovação do Comitê de Ética em Pesquisa, respeitando a resolução 466/12 do Conselho Nacional de Saúde - Comissão Nacional de Ética em Pesquisa (CONEP), com parecer favorável sob o protocolo CAAE: 10206912.2.0000.5402.
} 
modalidade a distância e com o uso de tecnologias de informação e comunicação. Desse modo, o AVA-Moodle foi organizado com abas superiores indicando o Módulo em andamento e a respectiva semana de atividade. Cada semana era disponibilizada aos professores cursistas de forma gradativa, respeitando o cronograma das atividades.

Os instrumentos selecionados na intervenção foram utilizados tanto para promover a formação continuada das professoras participantes quanto para a coleta de dados da pesquisa. São eles: o questionário, as narrativas escritas derivadas do fórum de discussão e das atividades realizadas pelos participantes, individual ou coletivamente.

Cabe esclarecer, que apesar de existir eixos temáticos norteadores para o currículo e um planejamento da proposta inicial, de acordo com a abordagem teórico-metodológica adotada, foi possível a sua reconfiguração a partir da identificação das expectativas dos professores cursistas, bem como ao longo do seu desenvolvimento de acordo com as demandas que surgiam a partir das práticas e experiências dos participantes da pesquisa.

Para este estudo, a análise esteve focada em como a Fonoaudiologia pode subsidiar e contribuir com a construção ou ampliação de saberes possibilitando o entendimento a respeito do aprendizado da linguagem escrita e dos problemas de aprendizagem.

Inicialmente a análise foi organizada a partir de uma leitura de forma mais livre e uma segunda leitura de modo a inicialmente identificar temas que eram tratados ou emergiam a partir da narrativa dos professores cursistas. Posteriormente, utilizamos os procedimentos de análise de conteúdo que tem como ponto de partida a mensagem, por expressar significado e sentido, "oral, escrita, gestual, silenciosa, figurativa, documental ou diretamente provocada", além de se articular com as condições contextuais dos sujeitos (FRANCO, 2008, p. 19).

\section{Algumas considerações a tecer}

As Diretrizes Curriculares Nacionais para a formação inicial em nível superior e para a formação continuada (BRASIL, 2015), em seu artigo $3^{\circ}$, aponta que a formação continuada se destina

[...] a preparação e ao desenvolvimento de profissionais para as funções do magistério na educação básica em suas etapas - educação infantil, ensino fundamental, ensino médio - [...] a partir da compreensão ampla e contextualizada de educação e educação escolar, visando assegurar a produção e difusão de conhecimentos de determinada área e a participação na elaboração e implementação do projeto político-pedagógico da instituição, na perspectiva de garantir, com qualidade, os direitos e objetivos da aprendizagem e o seu desenvolvimento. (BRASIL, 2015, p. 3-4).

Desse modo, consideramos que a Fonoaudiologia e Educação são áreas de saberes que interagem e se interseccionam para a construção de um novo saber prático visando à formação continuada de professores dos anos iniciais do ensino fundamental em uma perspectiva interdisciplinar.

Sob essa perspectiva de integração profissional, a relação professorfonoaudiólogo prevê que esses profissionais se considerem co-autores de ações que visam não apenas à promoção da saúde, mas também ao resgate tanto do espaço pedagógico, como meio propício para a promoção da aprendizagem, quanto do papel do professor em tal promoção. (GIROTO, 2005, p. 55).

Conforme a seguinte definição para Fazenda (2008, p. 99): 
DOI: $10.12957 /$ teias. $\%$ Y.55792

A interdisciplinaridade na formação profissional requer competências relativas às formas de intervenção solicitadas e às condições que concorrerem ao seu melhor exercício. Neste caso, o desenvolvimento das competências necessárias requer a conjugação de diferentes saberes disciplinares. Entenda-se por saberes disciplinares: saberes da experiência, saberes técnicos e saberes teóricos interagindo dinamicamente sem nenhuma linearidade ou hierarquização que subjugue os profissionais participantes.

Isso significa que a prática interdisciplinar se mostra necessária diante do público que a escola comporta, das demandas referentes ao aprendizado dos estudantes e de uma maior comunicação entre a equipe escolar (gestor, orientador, professor e demais funcionários) no intuito de desmitificar a visão patológica que vem substanciando a educação, visto que "[...] falhando em sua tarefa pedagógica, a escola passa a apontar cada vez mais uma série de 'patologias' nas crianças" (SMOLKA, 1996, p. 17).

De acordo com Giroto (2005), a despatologização é possível a partir do momento em que compreendemos e, não mais, nos referirmos ao erro como aquilo que extrapola a normalidade caracterizando-o como um sintoma do não aprender. Mas, sim, entendê-lo como resultado do processo singular da criança diante do aprendizado da linguagem escrita.

Acreditamos que esta prática na Educação, por meio da formação continuada, pode auxiliar o professor a entender o estudante como um ser singular, cada qual com suas peculiaridades. Ferreira (2001, p. 34) complementa ao referir que "a interdisciplinaridade surge, assim, como possibilidade de enriquecer e ultrapassar a integração dos elementos do conhecimento".

A formação na educação à, pela e para a interdisciplinaridade se impõe e precisa ser concebida sob bases específicas, apoiadas por trabalhos desenvolvidos na área, trabalhos esses referendados em diferentes ciências que pretendem contribuir desde as finalidades particulares da formação profissional até a atuação do professor. (FAZENDA, 2001, p.14).

É importante frisar que não afirmamos que o problema está somente na formação dos professores, mas que esta é uma das alternativas para minimizar a crise da aprendizagem e um dos caminhos para a melhoria da educação e, principalmente, do ensino. Desta forma, concordamos com André (2010, p. 176) ao afirmar que é primordial:

[...] descobrir os caminhos mais efetivos para alcançar um ensino de qualidade, que se reverta numa aprendizagem significativa para os alunos. Isso supõe, por um lado, um trabalho colaborativo entre pesquisadores da universidade e os professores das escolas, e por outro lado um esforço analítico muito grande, seja no interior dos grupos de pesquisa, seja entre grupos para reunir elementos que ajudem a reestruturar as práticas de formação.

Isto significa que se espera que o professor seja capaz de valorizar a diversidade utilizandoa a seu favor e criando estratégias de ensino diversificadas para ensinar a todos os estudantes com ou sem deficiência independentemente de sua condição social, cultural, biológica, linguística e emocional.

Nessa perspectiva, Fusari (1989) defende que os professores, por meio do conhecimento e de uma análise crítica, devem identificar os problemas para elaborar ações na tentativa de superar a situação, caso contrário, se não tiverem a clareza podem causar danos profundos e irreversíveis aos estudantes. O autor ressalta a importância do planejamento e do plano de ensino na prática do professor, considera-os imprescindíveis para a ação e reflexão do docente, já que a sua competência-compromisso transforma a realidade da sala de aula. 
DOI: $10.12957 /$ teias. $\%$ Y.55792

Assim, é preciso que, o professor ao planejar suas atividades de ensino previamente determine o mínimo necessário a ser efetivamente aprendido pelo estudante (LUCKESI, 1992).

Sob essa ótica, acreditamos que a formação continuada de professores voltada para a compreensão do processo de aprendizagem, dos problemas de aprendizagem e de suas variáveis auxiliará na elaboração do planejamento e do plano de ensino de maneira que contemple as ações pedagógicas necessárias para o aprendizado dos estudantes considerando suas singularidades.

\section{POSSIBILIDADES E DESAFIOS DA TESSITURA: PERSPECTIVAS DE ARTICULAÇÃO ENTRE EDUCAÇÃO E FONOAUDIOLOGIA}

A análise foi realizada arrematando os nós da tessitura, a partir da triangulação dos dados oriundos do questionário de inscrição, das narrativas escritas individuais produzidas ao longo do módulo e do cotejo com a literatura, indicando as possibilidades e limitações da articulação entre Fonoaudiologia e Educação.

Desta forma, identificamos 6 grandes categorias, a saber: percepção dos professores diante dos problemas de aprendizagem, necessidades dos professores, saberes dos professores, contribuições da fonoaudiologia, desafios e entraves para a prática do professor e sentimentos dos professores.

\section{Percepção dos professores diante dos problemas de aprendizagem}

Os professores cursistas evidenciaram confusão de conceitos no que se refere ao o que compreendiam por problemas de aprendizagem. Aproximadamente $32 \%$ das respostas parecem oscilar entre a falta de conhecimento a respeito das Dificuldades de Aprendizagem, dos Distúrbios de Aprendizagem e da Dislexia. Além desses, suas narrativas denotaram não distinguir as dificuldades de outras patologias, transtornos ou deficiência, conforme alguns relatos coletados a seguir:

Tenho uma criança avaliada como limítrofe [...] (PC 1, Questionário - individual, $02 / 5 / 14)$

Déficit de atenção. (PC 2, Questionário - individual, 13/5/14)

Trabalho em uma sala de PIC [Projeto Intensivo no Ciclo] todos os alunos possuem dificuldades de aprendizagem. (PC 12, Questionário - individual, $03 / 5 / 14)$

Aluno com traços de autismo. (PC 19, Questionário - individual, 09/5/14)

Um fator preocupante se refere a necessidade de procurar algo que justifique o baixo desempenho dos estudantes ou o "não aprender" que, aliados ao desconhecimento, provoca uma gama de consequências para a criança, pois fatores extrínsecos podem interferir intrinsicamente interferindo significativamente em seu aprendizado. A esse respeito, Viégas e Oliveira (2014, p. 49) afirmam "que vivemos hoje uma verdadeira epidemia de diagnósticos, e não de doenças. Diagnóstico vago, para um transtorno de existência duvidosa".

Zorzi (2003) enfatiza que no ambiente escolar ocorre uma valorização das dificuldades razão pela qual muitas crianças são encaminhadas para diagnóstico e tratamento. Para o autor, o estudante não é avaliado

[...] pelo que mostra ser capaz de aprender e saber, mas sim pelo que ainda não faz e ainda não sabe. A própria escola ainda não foi capaz de perceber o seu 
DOI: $10.12957 /$ teias.\%Y.55792

poder de ensinar, pois nega aquilo que é fruto autêntico de sua atuação educacional. (ZORZI, 2003, p. 20).

Desse modo, se faz necessário repensar esse movimento, pois muitas crianças são vítimas, culpabilizadas, medicalizadas e estigmatizadas por "não aprender" sendo que existem múltiplos fatores interferindo. Acreditamos que independente da presença ou não de uma "patologia" a escola tem uma função social e o professor deve possibilitar o aprendizado destes estudantes, e não utilizar os rótulos como "muletas" para justificar as defasagens no aprendizado.

Nesse ínterim, a Fonoaudiologia tem muito a contribuir, auxiliando a escola e o professor a lidar com as singularidades.

\section{Necessidades formativas dos professores dos anos iniciais do ensino fundamental}

As narrativas das professoras cursistas PC1, PC2 e PC3 evidenciam o desafio de lidar com a rigidez de um currículo prescrito desconectado da realidade contemporânea e a premência de mudança ou transformação da prática dentre as principais necessidades formativas das PC, frente a cada conteúdo abordado e a sua prática em sala de aula, mostrando que conseguiram perceber e reconhecer a importância de seu papel no aprendizado da leitura e da escrita de seus estudantes, bem como a premência de ações coletivas e colaborativas para a transformação da prática e dos espaços da escola.

A situação pode ser transformada, visto que nós professores não podemos mudar a grade curricular, mas a metodologia escolhida pode e deve contemplar a realidade das nossas crianças [...] a grande mudança que preciso fazer é justamente na prática metodológica [...] os conteúdos estão muito desconectados da realidade das crianças isso gera desinteresse. [...] compreendo a necessidade de mudanças, percebo que essas devem começar com professor [...] (PC 1, Lição dissertativa - individual, 15/6/14)

[...] o mundo fora da escola parece sempre melhor. Mas, porque não trazer este mundo para dentro dela? Acredito que possamos fazer isso, eu pelo menos faço [...] não vejo uma escola centrada apenas em um livro didático que muitas vezes estão desconexos com a realidade local [...] acredito que a educação neste país se modifica quando o professor se modifica internamente. (PC 2, Lição dissertativa - individual, 16/6/14)

A escola precisa mudar drasticamente e, consequentemente, seus educadores. Para que isso ocorra é necessária uma reformulação na mente do educador [...] várias escolas continuam dessa mesma forma que o professor quer que seu aluno apenas reproduza o conteúdo [...] para que ocorra mudança primeiramente esse professor precisa de uma formação acadêmica adequada [...] possa entender como ocorre a aprendizagem [...] precisa refletir sobre seu papel de professor para que planejar aulas atrativas que estimulem a produção do conhecimento [...] precisamos refletir sobre nossas práticas a todo momento. (PC 3, Lição dissertativa - individual, 16/6/14)

Os professores não podem ser vistos como técnicos nem executores nem como meros reprodutores, mas como atores "autônomos de suas próprias práticas e como sujeitos competentes de sua própria profissão" (TARDIF, 2002, p. 243). Caso contrário, para Vasconcellos (2007, p. 70) o professor continua na sala de aula sem convicção, não acreditando no que faz e, por conseguinte, não realiza um bom trabalho. 
Em todas as narrativas analisadas é evidente que mudanças são necessárias na Educação e na prática do professor. Contudo, nota-se que as ações ficam estagnadas frente a uma luta solitária, às dúvidas emergentes, a um desejo embutido, às inúmeras adversidades enfrentadas no cotidiano escolar como frequência, sala numerosa, estudantes em diferentes níveis de aprendizado, falta de uma formação que contemple as necessidades, falta de apoio da gestão entre outros.

A partir dessa perspectiva, verificamos que tal realidade é vista como um obstáculo que impede a transformação e amplia a complexidade das necessidades formativas dos professores em exercício nos anos iniciais do ensino fundamental. Como refere Charlot (2008, p. 20) que as exigências do professor na contemporaneidade requerem uma conduta profissional que não faz parte da cultura tradicional uma vez que "[...] o professor, que não foi e ainda não é formado para tanto, fica um pouco perdido". Acredita que

quanto mais difíceis as condições de trabalho, mais predominam as estratégias de sobrevivência [...] são essas estratégias de sobrevivência, e não uma misteriosa "resistência à mudança", que freiam as tentativas de reforma ou inovação pedagógica. (CHARLOT, 2008, p. 23).

\section{Saberes dos professores}

A partir da concepção de Tardif (2006) os achados foram organizados como saberes relacionados com a prática pedagógica ao considerar o 'saber fazer' em relação à detecção dos problemas de aprendizagem, ao como ser capaz de planejar ações de ensino para ensiná-los, estimulá-los e entender como eles aprendem.

As estratégias de ensino empreendidas pelas PC, inicialmente se pautavam mais na assessoria individual, como se pode observar nos relatos de PC1, PC2 e PC3 respectivamente.

[...] trabalho mais individualizado no sentido de contribuir com a conclusão do processo de alfabetização. (PC 1, Questionário - individual, 02/5/14)

Atividades diversificadas. (PC 2, Questionário - individual, 13/5/14)

Atuo intervindo e auxiliando na realização das atividades. (PC 3, Questionário individual, 05/5/14)

No decorrer do curso, as trocas entre os pares, pesquisadora formadora e as tutoras, foi possível perceber algumas alterações que se direcionam para a importância de incentivar o interesse dos alunos, entendimento do plano de ensino como norte para estabelecer metas a serem alcançadas com os estudantes, diversificar os recursos utilizados para ensinar e na forma de fazer intervenções

[...] deve contemplar a realidade das nossas crianças [...] despertar [...] curiosidade e interesse [...] nossos alunos precisam ser estimulados para que o desejo de aprender possa surgir. (PC 1, Lição dissertativa - individual, 15/6/14)

[...] apenas copiando o aluno não aprende. Ele precisa interagir e para isso o professor tem que fazer a intervenção necessária para construção de conhecimentos e não a mera reprodução deles [...] ele precisa refletir sobre seu papel de professor para que planeje aulas atrativas que estimulem a produção do conhecimento [...] procuro atividades que estejam no seu nível para poder, a partir do seu conhecimento propor atividades desafiadoras [...] cobro bastante dos alunos o estudo, às vezes penso que poderia ser mais flexível. (PC 3, Lição dissertativa - individual, 16/6/14) 
DOI: $10.12957 /$ teias. $\%$ Y.55792

[...] construção de uma prática pedagógica mais voltada para as diferentes maneiras de aprender [...] (PC 1, Memorial reflexivo - individual, 20/07/14)

Nesse sentido, os saberes aparentemente mobilizados pelas professoras cursistas ao longo do tempo remetem ao "[...] saber proveniente de sua própria experiência na profissão, na escola e na sala de aula" (TARDIF, 2006, p. 63). Em relação à construção e ampliação de saberes advém da experiência no exercício profissional e da troca com os pares, momento em que cada PC é considerada como protagonista de sua prática e desenvolve capacidades envolvendo diferentes perspectivas intelectuais, afetivas, morais e culturais.

\section{Contribuições da Fonoaudiologia na formação continuada de professores}

Outra categoria determinada foi as contribuições da Fonoaudiologia na formação continuada de professores como uma colaboração que favoreceu a revisão de saberes de forma a complementar e auxiliar o fazer pedagógico no cotidiano da sala de aula em que muitos professores se veem sozinhos para enfrentar os desafios vivenciados com sua turma.

As narrativas das professoras cursistas evidenciaram a contribuição da Fonoaudiologia por meio do trabalho colaborativo tanto em relação a parte teórica quanto na busca de soluções (planejamento e feedback da pesquisadora) para lidarcom uma sala heterogênea e com o enfrentamento dos problemas de aprendizagem. Tal fato corrobora com as concepções de Capellini et al (2009) quanto ao papel do fonoaudiólogo nas orientações e sugestões para a prática do professor, favorecendo o desempenho dos estudantes.

[...] muitas são as discussões sobre os problemas de aprendizagem [...] necessidade urgente de ações para transformar esse cenário [...] sonho com reuniões para professores totalmente voltadas para aquele que aprende, busca de soluções [...] (PC 1, Memorial reflexivo - individual, 28/6/14)

[...] o olhar daquele que está de fora do processo e pertencente a outra área contribui para que pontos não observados possam ser contemplados [...] trabalhar com parcerias dentro e fora da unidade escolar [...] os problemas não são discutidos coletivamente em busca de discussões [...] (PC 1, Memorial Reflexivo - individual, 20/7/14)

[...] foi válida a intervenção de outro profissional no planejamento. Às vezes um olhar de fora acrescenta algo que era necessário e não vemos [...] (PC 2, Memorial Reflexivo - individual, 20/7/14)

[...] Acho que o planejamento coletivo foi positivo porque as cursistas puderam interagir e trocar algumas ideias, mas o trabalho em grupo a distância foi um pouco difícil devido aos horários de trabalho das cursistas e a falta de diálogo. (PC 3, Memorial Reflexivo - individual, 22/7/14)

[...] me realizei discutindo as questões que envolvem os conceitos de distúrbios e dificuldades de aprendizagem, diferenciando-os [...] Tudo isso foi contemplado nesse módulo.[...] percebo total ausência de informações sobre como se dá aprendizagem em cada indivíduo, isso contribui para que as pessoas acreditem que podem nivelar a maneira como cada sujeito constrói o conhecimento [...] isso ficou muito claro com as contribuições da fonoaudiologia, onde foi possível compreender melhor como isso ocorre.(PC 1, Avaliação final - individual, 20/10/14) 
DOI: $10.12957 /$ teias. $\%$ Y.55792

Foi conhecer e ter a oportunidade de aprofundar os conhecimentos sobre o tema. Bem como a reflexão sobre as dificuldades que são encontradas na sala de aula. Pensar sobre a sala de aula como um todo, principalmente na aquisição da escrita foi muito bom para meu crescimento profissional [...] A falta de aprofundamento sistematizado sobre o assunto (o curso ajudou nisso) [...] $\mathrm{O}$ conhecimento técnico sobre o assunto. (PC 2, Avaliação final - individual, 22/10/14)

[...] a importância de um trabalho interdisciplinar entre professores e fonoaudiólogos, pois estes podem contribuir com o trabalho do professor oferecendo conhecimentos para a construção de estratégias pedagógicas que favoreçam o aprendizado de todos os alunos [...] Através da contribuição da fonoaudiologia pude rever minha prática e melhorar as minhas aulas com jogos atraindo a atenção e despertando o interesse dos alunos resultando em alunos alfabetizados. (PC 3, Avaliação final - individual, 21/10/14)

Tais práticas vão ao encontro dos apontamentos de Nóvoa (2007) quando destaca a importância dos professores se apropriarem de um conjunto de novas áreas de saber para integrarem à sua prática de ensino consolidando um trabalho colaborativo. E, ainda, acrescenta que a profissão professor é uma das que “[...] se colabora menos, do ponto de vista profissional [...] do ponto de vista do gesto profissional, do dia-a-dia profissional, da rotina, há um grande déficit de colaboração" (NÓVOA, 2007, p. 13).

Assim, podemos dizer que as redes tecidas entre as duas áreas integram a concepção de Fazenda (2008) quando ressalta que o olhar interdisciplinar induz a superações e até reformulações de saberes e de práticas profissionais, porém

Estamos tão habituados à ordem formal convencionalmente estabelecida, que nos incomodamos quando somos desafiados a pensar a partir da desordem ou de novas ordens que direcionam provisórias e novas ordenações. (FAZENDA, 2008, p. 24).

Essas considerações convergem para um desafio político-pedagógico para o aprendizado de todos estudantes (com e sem problemas de aprendizagem) enquanto uma atividade prática urgente e cotidiana "[...] que se transforma - e precisa ser pensada - enquanto se realiza" (SMOLKA, 1996, p. 113).

\section{Desafios e entraves para a prática de ensino}

As narrativas das professoras cursistas inicialmente continham aspectos que caracterizamos como desafios e entraves para a prática de ensino por indicar desilusão e desânimo com a carreira, um estado de "sem saída", isto é, de caminhos que pudessem lhes conduzir a práticas mais bem-sucedidas. Processual e gradativamente, as PC foram adquirindo motivação e uma outro olhar para a realidade do contexto escolar e de sua sala de aula com um novo ânimo, a partir de novas perspectivas e possibilidades de ação e intervenção didática.

[...] percebo que alguns professores (iniciantes) não vem mais com "espírito de mudança", pelo contrário vem em busca de uma muleta, no caso o livro didático, como se não soubesse o que fazer perante 30 alunos (não os culpo, pois, a formação dos professores deixa a desejar) [...] (PC 2, Lição dissertativa individual, 16/6/14) 
DOI: $10.12957 /$ teias. $\%$ Y.55792

[...] Precisamos refletir sobre nossas práticas a todo momento [...] encontro muitas dificuldades na minha prática diária principalmente com os alunos com dificuldades de aprendizagem. (PC 3, Lição dissertativa - individual, 16/6/14)

[...] É um absurdo perceber que ainda existem crianças com 10 anos que após passarem anos dentro de uma escola, 200 dias por ano e nada ou quase nada foi feito para transformar a sua realidade de fracasso escolar (PC 1, Memorial reflexivo - individual, 28/6/14)

[...] como garantir o diferenciado o tempo todo [...] como ter 30 aulas diferentes? (PC 2 Memorial reflexivo - individual, 29/6/14)

Trabalho com turmas de $5^{\circ}$ ano e percebo que nessa etapa o professor precisa correr para dar conta de tudo que se perdeu ao longo dos anos, desde o início da alfabetização. (PC 1, Memorial reflexivo - individual, 20/7/14)

[...] confesso que tenho dificuldade de trabalhar em grupo, apesar de fazer. Tento ser solidária, mas não sei lidar com "tempo do outro". [...] durante o planejamento coletivo até há a tentativa, mas só a tentativa, pois os discursos vazios e as discussões intermináveis acabam sempre no nada. (PC 2, Memorial reflexivo - individual, 20/7/14)

[...] A necessidade de deixar tudo homogêneo inviabiliza o processo de alfabetização, deixando muitas crianças a margem desse processo. Ignorar o contexto de vida, as experiências vivenciadas anteriores a chegada a escola, favorecem o fracasso escolar [...] (PC 1, Avaliação final - individual, 20/10/14)

Tais excertos parecem ecoar como pedidos de socorro diante da realidade de um sistema de ensino que exige resultados satisfatórios de desempenho, mensurados por meio das avaliações externas. Além disso, evidencia-se a luta diária e solitária dos professores dentro da sala de aula para operacionalizar um currículo desconectado da realidade em que vivemos e que cada vez mais distancia o estudante da escola.

Nesse sentido, concordamos com os apontamentos de Charlot (2012) quando menciona a importância de pensar o que se pode fazer nas condições reais da sala de aula inferindo que a escola é um lugar em que a maioria das vezes ensina coisas que só têm sentido ali dentro e não têm nenhum sentido fora dela (CHARLOT, 2012).

Outro aspecto que aparece com ênfase nas narrativas é a culpabilização da família:

[...]. falta de recurso, interesse dos pais (em alguns momentos), desinteresse dos alunos. (PC 2 Memorial reflexivo - individual, 20/7/14)

[...] falta de comprometimento das famílias; despreparo por partes de alguns professores, alguns não tem perfil de alfabetizador; o número excessivo de alunos por sala; a falta de currículo definido para o ciclo I do ensino fundamental. (PC 2, Avaliação final - individual, 22/10/14)

[...] A falta de formação no curso de Pedagogia, aos modismos das teorias e métodos de alfabetização e o grande número de alunos por sala, que interferem na qualidade do ensino [...] falta de apoio familiar às crianças e muitas dificuldades e distúrbios de aprendizagem que muitas vezes são diagnosticados por especialistas de forma tardia. (PC 3, Avaliação final - individual, 21/10/14)

Destarte, Garcia (1999) menciona que é comum os professores atribuir os entraves às famílias por não participarem da vida escolar de seus filhos. Entretanto, identificamos alguns elementos que relevantes e que nos chama a atenção, sendo eles: a sobrecarga de atividades 
DOI: $10.12957 /$ teias. $\%$ Y.55792

impostas, a necessidade de um diagnóstico com um discurso de que irá nortear as estratégias do professor, a falta de tempo para os professores dialogarem e trocarem experiências, o ensino autoritário, ausência de um trabalho coletivo, a falta de valorização de um plano de ensino entre outros.

\section{Sentimentos dos professores}

Todas as narrativas têm incorporados os sentimentos dos professores tanto positivos quanto negativos. Sendo assim, essa categoria foi criada considerando as esperanças, os desejos, a motivação, a criticidade, as angústias, o instinto de sobrevivência, impotência diante a tantos entraves e desafios.

[...] Às vezes penso que o conceito de aprendizagem que tenho não combina com as propostas educacionais que norteiam o contexto escolar, isso mesmo os tinha isso faz com que me sinta solitária nessa luta [...] sinto-me impotente [...] sensação que para sobreviver tenho a sensação que para sobreviver dentro desse contexto preciso me curvar ao sistema e a equipe gestora [...] mudar é preciso sempre, mas exige coragem, ousadia, determinação e muita estrutura psicológica. (PC 1, Lição dissertativa - individual, 15/6/14)

[...] até mesmo os mais experientes estão cansados de tantos discursos vazios de melhoria na educação que não vejam até mesmo esse ensino autoritário de mostrado na figura funcionar [...] "a esperança é a última que morre" não é esse o ditado mais usado no Brasil (PC 2, Lição dissertativa - individual, 16/6/14)

[...] Espero viver para ver planejamentos reais, com propostas claras, envolvendo pais e toda comunidade na busca por melhores condições de ensino e aprendizagem. (PC 1, Memorial reflexivo - individual, 20/7/14)

Em relação aos sentimentos negativos, a análise evidencia o que Charlot (2012) em seus estudos a respeito do professor constatou: de que muitas vezes se apresenta como vítima, mas pouco fala do prazer de ser professor e de ver o brilho nos olhos dos estudantes.

Face a esse contexto, Vasconcellos (2007, p. 78) defende que se o professor não tomar uma atitude e assumir o seu papel ele "[...] quebra-se como pessoa [...] perde a paixão, o entusiasmo, esgarça sua condição de sujeito de transformação. Por isso é tão delicado: fazer é muito exigente; não fazer é morrer!"”.

Por fim, pudemos compreender que a articulação com outra área de saber e a (re) significação de saberes profissionais despertou sentimentos positivos e de esperança aos professores, evidenciando um fator decisivo para a transformação da prática.

\section{CONCLUSÃO}

O formato metodológico assumido apresentou um caráter positivo diante da flexibilidade em adequar e (re)construir o currículo, considerando as necessidades e expectativas iniciais apresentadas pelas professoras e aquelas que emergiam no decorrer do programa. Entretanto, mostrou-se especialmente dilemático por se tratar de um programa vinculado a uma atividade de pesquisa, cujo tempo difere muito do tempo da escola e dos anseios cotidianos dos professores.

A busca em atender às necessidades que emergiam tornou-se especialmente desafiadora para não perder de vista o objetivo da pesquisa sem transformar a experiência em mera assessoria sem que a mesma provocasse a mobilização, construção ou reconstrução de saberes. 
A priore verificamos que a percepção das professoras cursistas a respeito da aprendizagem e seus problemas era equivocada e limitada, a existência do hábito de realizar suposições diagnósticas com aqueles estudantes em defasagem e faz parte da rotina da prática pedagógica o encaminhamento para os profissionais da saúde. Isso significa um olhar do professor centrado apenas nas características biológicas dos estudantes em defasagem.

No decorrer do programa, as narrativas foram se modificando e denotaram um olhar mais macro sobre o estudante nos permitindo verificar que entre as professoras cursistas houve compreensão a respeito da aprendizagem e problemas de aprendizagem, da importância do papel e da intervenção pedagógica do professor para o aprendizado da linguagem escrita.

Isto mostra um ponto positivo e relevante do trabalho de articulação dos saberes da Fonoaudiologia em relação ao processo de aprendizagem da linguagem escrita: o que é aprender, quais as variáveis intervenientes, como ocorre e o que é o sistema de escrita da Língua Portuguesa, como primordiais na experiência formativa para os professores. Aspectos esses visíveis nas narrativas a respeito da construção de um novo aprendizado, bem como o interesse em aprofundar o assunto.

Entretanto, ao analisarmos a efetividade do conteúdo abordado na prática pedagógica das professoras cursistas, verificamos que, ao transporem esses saberes construídos e ressignificados em um trabalho prático de planejamento e intervenção didática, esse constitui o grande "nó", pois houve dificuldades no planejamento coletivo e no planejamento de ensino (individual). A elaboração estava voltada para uma sala homogênea e, talvez, muitos professores se viram limitados sobre o que fazer e como trabalhar o conteúdo face a heterogeneidade em sala de aula.

Diante disso, identificamos a existência de lacunas no ambiente escolar em relação as diferentes práticas de ensino e oportunidades para um público que está à margem da política de inclusão. Uma vez que a escola é considerada um espaço fundamentalmente de trabalho coletivo, colaborativo, de (re)significação do saber docente e das políticas educacionais.

Concluímos que a pesquisa vai ao encontro do momento histórico que a Fonoaudiologia vivencia no Brasil no contexto educacional, rompendo com alguns paradigmas e abrindo um leque de atuação fonoaudiológica, para além da área da saúde (clínica), auxiliando o professor a fomentar práticas de ensino em sala de aula que privilegiem todos os estudantes. Indo mais além, construir e efetivar um trabalho em equipe, auxiliar no gerenciamento de conflitos entre outras competências que podem ser melhor exploradas.

No que se refere à Educação, entendemos que é uma área complexa e oferece muitas oportunidades para a atuação da Fonoaudiologia ainda a se explorar e conquistar. Como por exemplo, atuar na formação continuada de professores contribuindo na tessitura de um trabalho sólido, significativo, sério, colaborativo e sempre aberto a novas construções.

Desse modo, fica claro a premência de um trabalho colaborativo interdisciplinares entre esses saberes, principalmente, no planejamento de práticas de ensino que promovam um impacto significativo no aprendizado da leitura e da escrita de todos os estudantes.

\section{REFERENNCIAS}

ANDRÉ, Marli. Formação de professores: a constituição de um campo de estudos. Educação, Porto Alegre, v. 33, n. 3, p. 174-181, set./dez, 2010.

BRASIL. Lei no6.965, de 9 de dez̧embro de 1981. Dispõe sobre a regulamentação da profissão de fonoaudiólogo, e determina outras providências . Disponível em: http://www.planalto.gov.br/ccivil 03/leis/L6965.htm . Acesso em: 23 set. 2018. 
DOI: $10.12957 /$ teias. $\%$ Y.55792

BRASIL. Ministério da Educação. Conselho Nacional de Educação. Resolução no 2, de 1 de julho de 2015. Define as Diretrizes Curriculares Nacionais para a formação inicial em nível superior (cursos de licenciatura, cursos de formação pedagógica para graduados e cursos de segunda licenciatura) e para a formação continuada. [Portal] Ministério da Educação, Brasília, [2015]. Disponível em: http:/ / portal.mec.gov.br/index.php?option $=$ com docman\&view $=$ download\&alias $=17719$-rescne-cp-002-03072015\&category slug=julho-2015-pdf\&Itemid=30192 . Acesso em: 26 set. 2016.

CAPELLINI, Simone Aparecida et al. Avaliação e diagnóstico fonoaudiológico nos distúrbios de aprendizagem e dislexias. In: ZORZI, Jaime Luiz; CAPELLINI, Simone Aparecida (Org.). Dislexia e outros distúrbios da leitura-escrita: letras desafiando a aprendizagem. São José dos Campos: Pulso, 2009. p. 81-94.

CAPELLINI, Simone Aparecida; GERMANO, Gisele Donadon.; CUNHA, Vera Lucia Orlandi. Aprendizagem e habilidades acadêmicas. In: PANTANO, Telma; ZORZI, Jaime Luiz. (Org.). Neurociência aplicada à aprendizagem. São José dos Campos: Pulso, 2009. p. 125-139.

CHARLOT, Bernard. O professor na sociedade contemporânea: um trabalhador da contradição. Revista Educação e Contemporaneidade, Salvador, v. 17, n. 30, p. 17-31, jul./dez. 2008. Disponível em: http://www.uneb.br/revistadafaeeba/files/2011/05/numero30.pdf . Acesso em: 10 jun. 2014.

CHARLOT, Bernard A mobilização no exercício da profissão docente. Revista Contemporânea de Educação, v. 7, n. 13, jan./jul. 2012. Disponível em: http://revistas.ufrj.br/index.php/contempeduc/article/view/1655/1504 . Acesso em: 15 fev. 2014.

CONSELHO FEDERAL DE FONOAUDIOLOGIA. Resolução n 309, de 01 de abril de 2005. Dispõe sobre a atuação do Fonoaudiólogo na educação infantil, ensino fundamental, médio, especial e superior, e dá outras providências. Conselho Federal de Fonoaudiologia, Brasília, [2005]. Disponível em: http://www.fonoaudiologia.org.br/legislacaoPDF/Res $\% 20309 \% 20$ \%20Atua\%C3\%A7\%C3\%A30\%20Escolas.pdf. Acesso em: 10 mai. 2017.

ELLIOT, John. Recolocando a pesquisa-ação em seu lugar original e próprio. In: GERALDI, Corinta Maria Grisolia; FIORENTINI, Dario; PEREIRA, Elisabete Monteiro de Aguiar. (Org.). Cartografias do trabalho docente. Campinas: Mercado de Letras, 2001. p. 137-152.

FAZENDA, Ivani Catarina Arantes. Interdisciplinaridade e transdisciplinaridade na formação de professores. Revista do Centro de Educação e Letras da Unioeste, Foz do Iguaçu, v. 10, n. 1, p. 93-103, 2008.

FAZENDA, Ivani Catarina Arantes (Org.). Práticas interdisciplinares na escola. 7. ed. São Paulo: Cortez, 2001.

FERREIRA, Sandra Lucia. Introduzindo a noção de interdisciplinaridade. In: FAZENDA, Ivani Catarina Arantes (Org.). Práticas interdisciplinares na escola. 7. ed. São Paulo: Cortez, 2001. p. 33-35.

FUSARI, José Cerchi. A formação continuada de professores no cotidiano da escola fundamental. Série Ideias, São Paulo, n. 12, p. 25-34, 1992.

FRANCO, Maria Laura Puglisi Barbosa. Análise do conteúdo. 3. ed. Brasília: Liber Livro, 2008.

GARCIA, Carlos Marcelo. Formação de professores: para uma mudança educativa. Porto: Porto, 1999.

GIROTO, Cláudia Regina Mosca. A parceria entre o professor e o fonoaudiólogo: um caminho possível para a atuação com a linguagem escrita. 2005. 256 f. Tese (Doutorado em Educação) - Faculdade de Filosofia e Ciências, Universidade Estadual Paulista, Marília, 2005. 
LANUTI, José Eduardo de Oliveira Evangelista. Educação matemática e inclusão escolar. 2015. 127 f. Dissertação (Mestrado em Educação) - Faculdade de Ciências e Tecnologia, Universidade Estadual Paulista, Presidente Prudente, 2015.

LEONARDO, Nilza Sanches Tessaro.; BRAY, Cristiane Toller; ROSSATO, Solange Pereira Marques. Inclusão escolar: um estudo acerca da implantação da proposta em escolas de ensino básico. Revista Brasileira de Educação Especial, Marília, v. 15, n. 2, p. 289-306, maio/ago. 2009.

LUCKESI, Cipriano Carlos. Planejamento e avaliação na escola: avaliação e necessária determinação ideológica. Série Ideias, São Paulo, n. 15, p. 115-125, 1992. Disponível em: http://www.crmariocovas.sp.gov.br/int_a.php?t=014. Acesso em: 10 jun. 2015.

MANTOAN, Maria Teresa Égler. Inclusão, diferença e deficiência: sentidos, deslocamentos, proposições. Inclusão e Sociedade, Brasília, DF, v. 10 n. 2, p. 37- 46, jan./jun. 2017.

MASUYAMA, Paula Mieco Koizumi. Tecendo redes entre Educaşão e Fonoandiologia: formação colaborativa e práticas de ensino possiveis. 2015. 132 f. Dissertação (Mestrado em Educação) - Universidade Estadual "Julio de Mesquita Filho", Unesp, Presidente Prudente.

MASUYAMA, Paula Mieco Koizumi; RINALDI, Renata Portela. Educação e Fonoaudiologia: práticas colaborativas de ensino. Curitiba: Appris, 2020

MIZUKAMI, Maria da Graça Nicoletti et al. Escola e aprendizagem da docência: processos de investigação e formação. São Carlos: EdUSFCAR, 2003.

NÓVOA, António. Desafios do trabalho do professor no mundo contemporâneo. São Paulo: SINPRO, 2007. PEÑA, Maria de los Dolores. Interdisciplinaridade: questão de atitude. In: FAZENDA, Ivani Catarina Arantes (Org.). Práticas interdisciplinares na escola. 7. ed. São Paulo: Cortez, 2001. p. 57-64.

PEREIRA, Elisabete Monteiro de Aguiar. Professor como pesquisador: o enfoque da pesquisaação na prática docente. In: GERALDI, Corinta Maria Grisolia; FIORENTINI, Dario; PEREIRA, Elisabete Monteiro de Aguiar. (Org.). Cartografias do trabalho docente. Campinas: Mercado de Letras, 2001. p. 153-181.

PIMENTA, Selma Garido. Pesquisa-ação crítico-colaborativa: construindo seu significado a partir de experiências na formação e na atuação docente. In: PIMENTA, Selma Garido; GHEDIN, Evandro; FRANCO, Maria Amélia Santoro. (Org.). Pesquisa em educação: alternativas investigativas com objetos complexos. São Paulo: Loyola, 2006. p. 25-64.

RIBAS, Angela; PAZINI, Solange. Fonoaudiologia e Educação: uma parceria necessária. Curitiba: UTP, 2010.

RIBAS, Angela; SERRATO, Maria Regina Franke. Atuação fonoaudiológica nas escolas. In: RIBAS, Angela; PAZINI, Solange. Fonoaudiologia e Educação: uma parceria necessária. Curitiba: UTP, 2010.

RINALDI, Renata Portela. Desenvolvimento profissional de formadores em exercício: contribuições de um programa on-line. 2009. 224 f. Tese (Doutorado em Educação) - Universidade Federal de São Carlos, São Carlos, 2009.

SMOLKA, Ana Luiza Bustamante. A criança na fase inicial da escrita: a alfabetização como processo discursivo. $7^{a}$ ed. São Paulo: Cortez, 1996.

TARDIF, Maurice. Saberes docentes e formação profissional. 7. ed. Petrópolis: Vozes, 2006.

TODOS PELA EDUCAÇÃO; MODERNA. Anuário Brasileiro da Educação Básica. São Paulo: Modernam, 2019. Disponível em: https://www.todospelaeducacao.org.br/_uploads/_posts/302.pdf. Acesso em: 10 jul. 2019. 
DOI: $10.12957 /$ teias. $\%$ Y.55792

UNESCO. Resumo do Relatório de Monitoramento Global da Educação 2020: Inclusão e Educação para todos. Paris: UNESCO, 2020. Disponível em: https://unesdoc.unesco.org/ark:/48223/pf0000373721 por/PDF/373721por.pdf.multi . Acesso em: 17 out. 2020.

UNESCO. Relatório de Monitoramento Global da Educação 2019: Migração, deslocamento e educaşão: construir pontes, não muros. Brasília: UNESCO, 2019. Disponível em: https://www.gcedclearinghouse.org/sites/default/files/resources/190008por.pdf. Acesso em: 05 set. 2019.

UNESCO. Relatório de Monitoramento Global de Educação para Todos 2013-2014. Ensinar e aprender: alcançar a qualidade para todos. Brasília: UNESCO, 2014. Disponível em: https://unesdoc.unesco.org/ark:/48223/pf0000225654 por. Acesso em: 05 set. 2019.

VASCONCELLOS, Celso dos Santos. Para onde vai o professor? Resgate do professor como sujeito de transformação. 12. ed. São Paulo: Libertad, 2007.

VIÉGAS, Lygia de Sousa; OLIVEIRA, Ariane Rocha Felício de. TDAH: conceitos vagos, existência duvidosa. Nuances, Presidente Prudente, v. 25, n. 1, p. 39-58, jan./abr. 2014. Disponível em: http://dx.doi.org/10.14572/nuances.v25i1.2736 . Acesso em: 15 abr. 2015.

ZORZI, Jaime Luiz. Aprendizagem da linguagem escrita: indo além dos distúrbios. In: ZORZI, Jaime Luiz. Aprendizagem e distúrbios da linguagem escrita: questões clínicas e educacionais. Porto Alegre: Artmed, 2003. p. 9-26.

Submetido em dezembro de 2020

Aprovado em março de 2021

\section{Informações do(a)(s) autor(a)(es)}

Paula Mieco Koizumi Masuyama

Doutoranda em Educação pela Universidade Estadual Paulista "Júlio de Mesquita Filho"- Campus de

Presidente Prudente

E-mail: paulamasuyama@gmail.com

ORCID: 0000-0002-4741-2673

Link Lattes: http:/ / lattes.cnpq.br/1229588862071456 